\title{
Experimental and Numerical Analysis of Parallel Reactant Flow and Transverse Mixing with Mineral Precipitation in Homogeneous and Heterogeneous Porous Media
}

\author{
Don T. Fox ${ }^{1}$ - Luanjing Guo ${ }^{2}$ - Yoshiko Fujita ${ }^{1}$. \\ Hai Huang ${ }^{1}$ - George Redden ${ }^{3}$
}

Received: 13 April 2015 / Accepted: 7 December 2015 / Published online: 17 December 2015

(C) The Author(s) 2015. This article is published with open access at Springerlink.com

\begin{abstract}
Formation of mineral precipitates in the mixing interface between two reactant solutions flowing in parallel in porous media is governed by reactant mixing by diffusion and dispersion and is coupled to changes in porosity/permeability due to precipitation. The spatial and temporal distribution of mixing-dependent precipitation of barium sulfate in porous media was investigated with side-by-side injection of barium chloride and sodium sulfate solutions in thin rectangular flow cells packed with quartz sand. The results for homogeneous sand beds were compared to beds with higher or lower permeability inclusions positioned in the path of the mixing zone. In the homogeneous and high permeability inclusion experiments, $\mathrm{BaSO}_{4}$ precipitate (barite) formed in a narrow deposit along the length and in the center of the solution-solution mixing zone even though dispersion was enhanced within, and downstream of, the high permeability inclusion. In the low permeability inclusion experiment, the deflected $\mathrm{BaSO}_{4}$ precipitation zone broadened around one side and downstream of the inclusion and was observed to migrate laterally toward the sulfate solution. A continuum-scale fully coupled reactive transport model that simultaneously solves the nonlinear governing equations for fluid flow, transport of reactants and geochemical reactions was used to simulate the experiments and provide insight into mechanisms underlying the experimental observations. Migration of the precipitation zone in the low permeability inclusion experiment could be explained by the coupling effects among fluid flow, reactant transport and localized mineral precipitation reaction.
\end{abstract}

Keywords Mixing - Coupled flow-transport-reaction processes $\cdot$ Mineral precipitation · Permeability

$凶$ Don T. Fox

Don.fox@inl.gov

$\bowtie$ George Redden

George.redden@coe.montana.edu

1 Idaho National Laboratory, Idaho Falls, ID, USA

2 University of Utah, Salt Lake City, UT, USA

3 Montana State University, Bozeman, MT, USA 


\section{Introduction}

Engineered mineral precipitation in the subsurface has been proposed as a method to modify contaminant mobility (Fujita et al. 2008; Moore et al. 2007; Szecsody et al. 2012; Warren et al. 2001), fluid flow paths (Ferris et al. 1996; Taron and Elsworth 2009) and geotechnical properties of consolidated media (Muynck et al. 2010; DeJong et al. 2006). Some engineering objectives, such as immobilizing contaminants in situ by co-precipitation or encapsulation, involve forming precipitates at a distance from where reactant solutions can be injected. The numbers and locations of injection wells are often limited by cost and physical obstacles. However, if the location and rate of in situ mixing of reactive solutions can be controlled, this would offer a means to manipulate the location of precipitation reactions and the effect precipitates will have on media properties and solution components.

Solution injection strategies can be varied to create and enhance mixing zones for reactants in porous media (Tartakovsky et al. 2008). One approach, which is the focus of this study, involves flowing two solutions in parallel such that lateral dispersion and diffusion generate a zone of reactant mixing between the solutions. In a study by Tartakovsky et al. (2008) of the side-by-side injection of solutions of calcium carbonate and sodium bicarbonate into a homogeneous porous medium, $\mathrm{CaCO}_{3}$ precipitation progressed along the mixing interface in a narrow band for the length of the sand bed. Katz et al. (2011) conducted a similar experiment and observed similar results. Katz et al. also reported observing a "mild shift" of the precipitate toward the carbonate side of the flow cell. In experiments conducted in our laboratory using calcium and carbonate solutions (data not published), we also observed that over the course of the experiments, the precipitation zone tended to migrate toward the carbonate-containing solution. Katz et al. suggested that the bias in the precipitate zone toward the carbonate side may have been due to the fact that in their experiments the $\mathrm{pH}$ of the sodium carbonate solution was higher than the $\mathrm{pH}$ of the calcium chloride solution, and calcium carbonate is more soluble at lower $\mathrm{pH}$.

In the study by Katz et al., the use of a continuum-based modeling approach limited the analysis of local or pore-scale permeability. In Tartakovsky et al. (2008), it was noted that the cumulative masses of injected calcium and bicarbonate were sufficient, in principle, to form an impermeable carbonate barrier in the zone of mixing. However, if an impermeable barrier were formed, the precipitate would be expected to dissolve since each individual solution was undersaturated with respect to calcium carbonate phases. The result was that the precipitation zone approached an "irreducible permeability," which was observed using dye tracers and simulated using a model based on Smoothed Particle Hydrodynamics. If the precipitation zone retains finite permeability, it should be possible to drive lateral movement of the mixing zone by changing the lateral pressure gradient through changes in the relative flow rates of the injected solutions.

However, in more realistic physically heterogeneous media, the location and properties of the mixing interface, and how precipitates are deposited, are more difficult to predict than for simple homogeneous media. Furthermore, direct observation of the mixing interface geometry and of flow path evolution in the field is also problematic because conventional sampling methods rarely have high positional accuracy and can obscure the physical and chemical properties of mixing zones as a consequence of concentration averaging during sample extraction. Understanding details of the physical-chemical coupling of precipitation processes in heterogeneous media can enhance our ability to engineer in situ mixing and precipitation. 
In order to expand on previous experiments involving carbonate precipitation in homogeneous media, we conducted $2 \mathrm{D}$ parallel flow experiments with barium chloride $\left(\mathrm{BaCl}_{2}\right)$ and sodium sulfate $\left(\mathrm{Na}_{2} \mathrm{SO}_{4}\right)$ in homogeneous and heterogeneous media. To simulate heterogeneous media, the flow cells were constructed with inclusions of higher or lower permeability positioned in the path that the solution-solution mixing interface would take in homogeneous media. Upstream and downstream faces of the inclusions were slanted relative to the direction of flow in homogeneous media to intentionally bias deviations in flow and to avoid possible flow instabilities (artifacts) that can occur in symmetrical, right-angle configurations. Non-symmetrical inclusion geometry is also more representative of natural media.

Barium $\left(\mathrm{Ba}^{2+}\right)$ and sulfate $\left(\mathrm{SO}_{4}^{2-}\right)$ solutions were used to form the mineral barite $\left(\mathrm{BaSO}_{4}\right) . \mathrm{BaSO}_{4}$ is a less complex chemical system than calcium carbonate, which is sensitive to $\mathrm{pH}$ conditions and reactions involving gas phases. There is only one polymorph (orthorhombic) of barite reported in the literature at low temperature and pressure, and it has low solubility; $\log K_{\mathrm{S}}^{\mathrm{o}}=-9.98$ at $25^{\circ} \mathrm{C}$ (Blount 1977 ). The barite system is also of engineering interest because it contributes to scale formation in oil and gas production and geothermal operation (Bozau et al. 2015), desalination, etc. and because of the ability of barite to form solid solutions with contaminants such as radium and lead (Curti et al. 2010; FernandezGonzalez et al. 2013; Zhang et al. 2014). The creation of a barite barrier in the subsurface, for example, could retard transport of contaminants around nuclear waste repositories.

In order to quantitatively interpret experimental observations, a fully coupled multicomponent reactive transport simulator (Gaston et al. 2012a, b; Guo et al. 2013) has been applied to investigate and better understand the coupling effects among flow, reactant transport and geochemical processes taking place in the system.

\section{Materials and Methods}

\subsection{Chemicals and Porous Media Characterization}

All chemicals, unless noted otherwise, were of ACS reagent grade, from Sigma-Aldrich (St. Louis, MO) or Fisher (Pittsburgh, PA). All solutions were prepared using 0.2- $\mu \mathrm{m}$-filtered nanopure water (18 megohms-cm; Barnstead, Dubuque, IA) and deaerated using the model 2100 Nold DeAerator by GeoKon (Lebanon, NH). The porous medium was Ottawa sand (US Silica, Ottawa, IL). Four grain sizes were used: ASTM grade 20 mesh $(\sim 0.850 \mathrm{~mm})$, 20-30 mesh $(0.600-0.850 \mathrm{~mm}), 50-70$ mesh $(0.212-0.300 \mathrm{~mm})$ and F-110 $(\leq 0.150 \mathrm{~mm})$. Each sand was packed into a 1D column for measurement of saturated hydraulic conductivity using the constant head method in accordance with ASTM D 2434 (Standard Test Method for Permeability of Granular Soils). Porosity $(\theta)$ was calculated as the ratio of the volume of water $\left(V_{\mathrm{w}}\right)$ needed to completely saturate the sand in the columns to the total volume $\left(V_{\mathrm{t}}\right)$ of the columns $\left(\theta=V_{\mathrm{w}} / V_{\mathrm{t}}\right)$. The volume of water was determined by mass assuming $1.0 \mathrm{~g}=1.0 \mathrm{~cm}^{3}$.

\subsection{Solution Preparation}

Sodium chloride $(\sim 7 \mathrm{~g} / \mathrm{L} \mathrm{NaCl})$ was added to the $\mathrm{Na}_{2} \mathrm{SO}_{4}(100 \mathrm{mM})$ solution to match its density to that of the $\mathrm{BaCl}_{2}(100 \mathrm{mM})$ solution. Solution density was measured as relative density, using an ASTM soil hydrometer with a glass cylinder (model 151H, ERTCO, USA). The final densities of the $\mathrm{Na}_{2} \mathrm{SO}_{4}$ and $\mathrm{BaCl}_{2}$ solutions were 1.015 and $1.016 \mathrm{~kg} / \mathrm{L}$, respectively, at $23^{\circ} \mathrm{C}(<0.1 \%$ difference). The $\mathrm{pH}$ was $\sim 7$ for both solutions. 
FD\&C red \#40 (0.22 g/L) and blue \#1 $(0.20 \mathrm{~g} / \mathrm{L})$ dye solutions were prepared in nanopure water equilibrated with the atmosphere $(\mathrm{pH} \sim 7)$. Dye solutions were density matched $(<0.1 \%$ difference) to the reactant solutions using $\mathrm{NaCl}(\sim 15 \mathrm{~g} / \mathrm{L}$ each). Matching the dye solution densities and injection rates with those of the reactant solutions enabled direct visual comparison of the mixing interface under non-reactive conditions to the mixing interface under reactive conditions.

The "background" solution was nanopure water $(\mathrm{pH} \sim 7)$ equilibrated with the atmosphere and also density matched to the dye and reactant solutions using $\mathrm{NaCl}(\sim 27 \mathrm{~g} / \mathrm{L})$. This background solution was used to displace solutions between dye and reactant injections and for the final sand pack flush.

\subsection{Flow Cell Construction, Packing and Operation}

Figure 1 shows the 2D flow cell setup. The cell was constructed using 1-cm-thick Lexan windows separated by $1-\mathrm{cm}$ Lexan spacers; the sand pack dimensions were $10 \mathrm{~cm}$ (width) $\times$

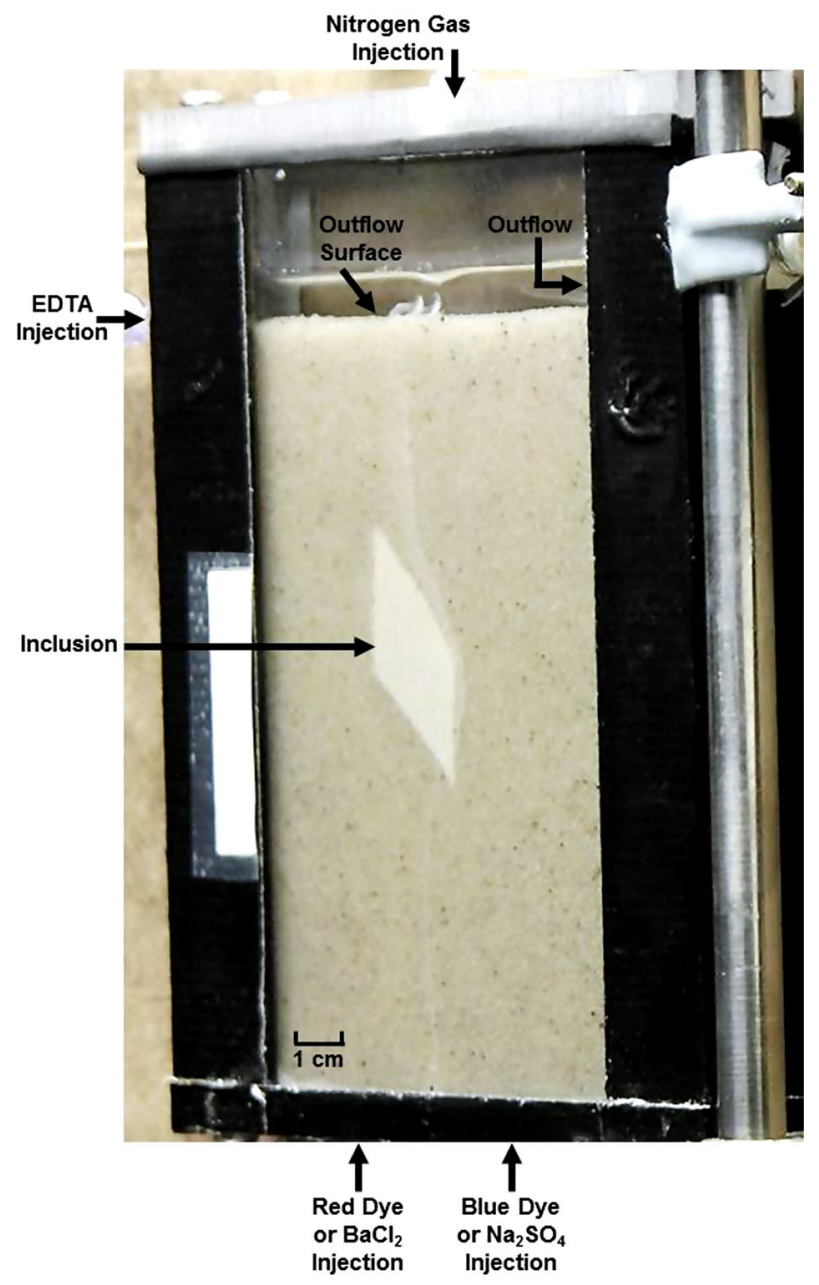

Fig. 1 Flow cell design (showing a low permeability inclusion) 
(a)

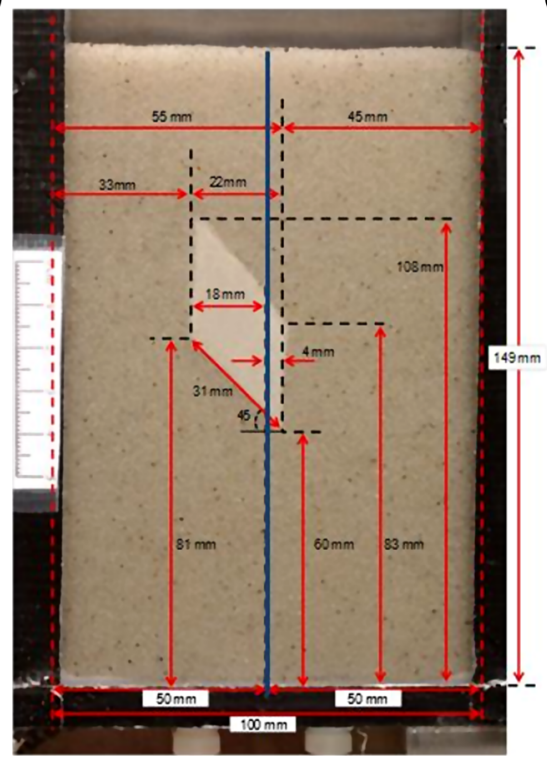

(b)

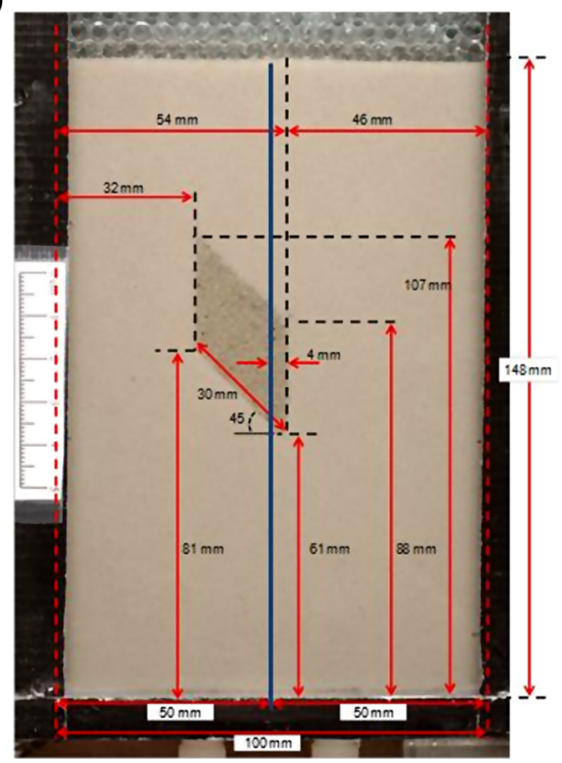

Fig. 2 Low permeability inclusion flow cell (a) and high permeability inclusion flow cell (b). In each flow cell experiment, the barium solution was injected from the bottom left and the sulfate solution from the bottom right. The blue line approximates the center of the solution-solution interface observed in homogeneous media

$15 \mathrm{~cm}$ (height) $\times 1 \mathrm{~cm}$ (thickness). There were two injection ports at the bottom for reactant introduction and one injection port at the top to introduce ethylenediaminetetraacetic acid (EDTA, $100 \mathrm{mM}, \mathrm{pH}$ 9) to inhibit $\mathrm{BaSO}_{4}$ precipitation downstream of the sand pack. The EDTA solution density was greater than the reactant solutions (adjusted with $\mathrm{NaCl}$ ) so that it would flow across the top of the sand media to prevent precipitation of $\mathrm{BaSO}_{4}$ at the outlet boundary. Nitrogen gas $(\sim 12 \mathrm{~L} / \mathrm{h}$.) was injected through a vent port to ensure continuous effluent evacuation and a non-fluctuating hydraulic head. Stainless steel screens (200 mesh) were placed over the bottom injection ports. Pulseless pumps (model PD100/SFSTQ, Fluid Metering Inc. Syosset, NY) were used to inject solutions into the flow cell from 40-L nitrogenpurged reservoirs that were fitted with carbon dioxide absorbent (Ascarite II) vents with desiccant (silica gel) pre-filters to minimize solution exposure to atmospheric carbon dioxide. Pump flow rates were calibrated prior to beginning the experiments (standard deviation $\left.1.4 \times 10^{-3} \mathrm{~mL} / \mathrm{min}\right)$.

The flow cell with homogeneous media was constructed using 20- to 30-mesh sand. For the heterogeneous media experiments, parallelogram-shaped low or high permeability inclusions were placed within the sand pack such that the mixing interface intersected the inclusion at a $45^{\circ}$ angle. This geometry was chosen to bias flow around one side of the inclusion. By doing so, the lateral position of the interface is established such that it would only deviate laterally in response to significant changes in upstream permeability. The low permeability inclusion consisted of F-110 mesh sand, set in a 20- to 30-mesh sand matrix. Figure 2a shows the low permeability inclusion flow cell; the measured dimensions for inclusion geometry and position were used for construction of the modeling domain. In the high permeability inclusion flow cell, shown in Fig. 2b, the inclusion consisted of 20-mesh sand placed within a 50- to 70-mesh sand matrix. For the high permeability inclusion flow cell, a 25-mesh nylon 
screen and 5-mm glass beads were placed on the downstream edge of the inclusion to confine the fine grained matrix.

Dry sand packs were initially purged with carbon dioxide followed by injection of deaerated nanopure water. During water saturation, flow cells were vibrated (model 290-01 Dremel) to achieve more consistent packing and forestall settling during experiments. Flow cells were rinsed with approximately 20 pore volumes of background solution. Pore volumes for the low permeability inclusion, high permeability inclusion and homogeneous flow cells were 55,56 and $53 \mathrm{~mL}$, respectively.

The same injection sequence was used for each of the 3 experiments. Following a preexperiment injection of colored dyes to characterize the mixing zone prior to precipitation, 10 pore volumes of background solution were injected prior to initiation of the precipitation experiment. Reactant solutions were injected for 250 pore volumes $(\sim 14 \mathrm{~L})$, followed by the background solution for 10 pore volumes. This was followed by a post-experiment dye injection. Finally, background solution was used to flush the dyes from the sand pack.

The flow cell experiments were conducted using $1.92 \mathrm{~mL} / \mathrm{min}$ for solutions on the left side (red dye, $\mathrm{BaCl}_{2}$, background) and $2.88 \mathrm{~mL} / \mathrm{min}$ for solutions on the right side (blue dye, $\mathrm{Na}_{2} \mathrm{SO}_{4}$, background); "left" and "right" are as shown in Fig. 2. The injection rates were chosen such that the mixing interface would intersect the inclusions near their vertical centerlines; the inclusions were not positioned exactly in the center of the flow cells. The same flow rates were used for the homogeneous flow cell for consistency. The total flow rate was confirmed periodically by manual measurement. Because the EDTA injection increased the fluid height over the sand pack, EDTA was also injected during the dye injections to maintain consistent hydrostatic pressure.

A digital camera (Nikon Dx2;50 mm lens) was used to record dye mixing and the formation of mineral precipitates during experiments. The camera was positioned to image the "front" of the flow cell as shown in Figs. 1 and 2. The photographic light source consisted of a box with 150 -watt fluorescent light tubes suspended $0.5 \mathrm{~m}$ above the flow cell; a black cloth shroud minimized light interference and helped to ensure stable illumination for image processing. Comparison of the images during a 1 pore volume imaging interval was used to determine when the mixing zone defined by the dyes was stable; this occurred within 5 pore volumes in all cases. Optical microscope images of undisturbed precipitates were taken at the conclusion of each experiment, from the same side of the flow cell as the Nikon camera. Microscope images were acquired using Leica Application Suite (LAS) software with a Leica digital camera (DFC450) and microscope (Z16 APOA).

At completion of the flow experiments, mineral cementation of the sand packs was evaluated after drying the sand by applying a vacuum to the injection ports and drawing air downward through the sand packs. The cells were then inverted to allow non-cemented sand to pour out. In all cases, the cemented sand layers were observed to be uniformly perpendicular to the observation faces of the cells and to have uniform thickness at a given height along the cell, indicating that the experiments were a reasonable facsimile of a 2-dimensional system.

\subsection{Reactive Transport Simulations}

In this study, we also applied a fully coupled reactive transport simulator, known as RAT (the acronym stands for ReActive Transport) to interpret experimental observations and gain better understandings on the coupling effects among flow, transport and reaction processes occurring in the flow cell. The RAT simulator adopts a preconditioned Jacobian-free Newton-Krylov (JFNK) nonlinear solution method to simultaneously solve all governing partial differen- 

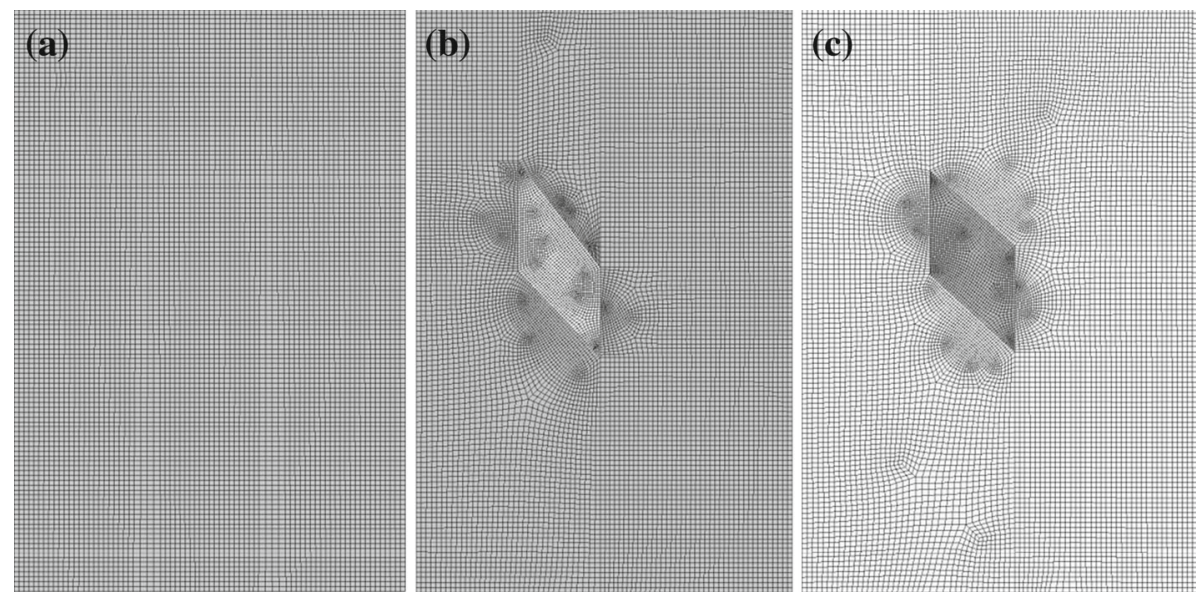

Fig. 3 Meshes used in simulations for homogeneous case (a), low permeability inclusion case (b) and high permeability inclusion case (c)

tial algebraic equations (PDAEs) for coupled flow and reactive transport processes in porous media. The JFNK solution method and the RAT simulator were described in detail in Guo et al. (2013). By simultaneously solving fluid flow, reactant transport and chemical reaction equations, RAT avoids decoupling errors associated with conventional operator-splitting solution approaches (Yeh and Tripathi 1989) and is well suited for tightly coupled reactive transport problems involving strong solution-medium geochemical interactions. For this study, the physical and chemical processes represented in RAT include fluid flow, solute transport, kinetic mineral precipitation and changes in medium porosity and permeability. Detailed aqueous speciation was not included in simulations since the chemical activities of other $\mathrm{Ba}^{2+}$ and $\mathrm{SO}_{4}^{2-}$ species are negligible under the experimental conditions.

The numerical model is two dimensional (2D) and has the same dimensions as the flow cell shown in Figs. 1 and 2. Figure 3 shows the meshes used for the three experimental setups: homogeneous packing (Fig. 3a), low permeability inclusion (Fig. 3b) and high permeability inclusion (Fig. 3c). The model domain is meshed with structured (homogeneous packing) and unstructured quadrilateral elements (with inclusions). Structures such as the injection ports and matrix/inclusion boundary are explicitly accounted for during meshing. In heterogeneous packing, a smaller base element size $(\sim 0.625 \mathrm{~mm})$ was used where grain sizes are small (e.g., inside the low permeability inclusion); a larger base element size $(\sim 1.25 \mathrm{~mm})$ was used where the grain sizes are relatively large (e.g., inside the high permeability inclusion). For homogeneous packing, uniform quadrilateral elements of size $\sim 1.25 \mathrm{~mm}$ were used in simulations. The selections of element sizes in simulations were dominated by the computational cost, observed widths of mixing and precipitation zones, grain size and size of inclusions. In general, element sizes are large enough to include enough number of grains in each element to allow the validity of continuum assumption, but still small enough to provide enough resolutions across those narrow mixing and precipitation zones observed in experiments.

The total simulated time periods were $5360 \mathrm{~s}$ for the homogeneous case, $5520 \mathrm{~s}$ for the low permeability inclusion case and 5920 s for the high permeability inclusion case. These times represent approximately 8 pore volumes of reactant injection; although the physical experiments lasted for 250 pore volumes, visible changes have ceased within 8 pore volumes 
and therefore a shorter simulation time was selected to reduce computational cost. In our simulations, we adopted a simple first-order rate model to describe the kinetics of barite precipitation

$$
R=\frac{d\left(C_{\mathrm{BaSO}_{4}}\right)}{\mathrm{d} t}=-R_{\mathrm{ref}}\left[1-\frac{C_{\mathrm{Ba}^{2+}} \cdot C_{\mathrm{SO}_{4}^{2-}}}{K_{\mathrm{eq}}}\right]^{n},
$$

where $R_{\text {ref }}$ is the reference apparent rate constant with $R_{\text {ref }}=A \cdot k_{\text {rate }}\left(\mathrm{mol} \mathrm{L}^{-1} \mathrm{~s}^{-1}\right) ; A$ is the specific reactive surface area; and $k_{\text {rate }}$ is the kinetic rate constant. $K_{\text {eq }}$ is the equilibrium constant for the precipitation reaction at the reference temperature. In all simulations, we chose to use the exponent $n=1$. Exponents greater than 1 (usually 2) for the term in brackets have been found to describe results for experiments in well-stirred reactors where surface reactions are the limiting process (e.g., Christy and Putnis 1993; Leung and Nancollas 1978) rather than diffusion. However, we assumed that in our studies, precipitation kinetics are likely to be diffusion limited due to incomplete mixing, further complicated by dispersion; support for this assumption was provided by the observation, as noted in Sect. 3, that dendritic morphologies for the $\mathrm{BaSO}_{4}$ precipitate were produced, consistent with diffusion-controlled precipitation (Dunn et al. 1999; Li et al. 2008).

Porosity changes induced by barite precipitation were calculated according to the amount of precipitate formed (Eq. (2); Brecevic and Kralj 2007). The associated permeability change with changing porosity follows a power law relationship with an exponent of 5.1 for closely packed sands (Eq. (3); Auset and Keller 2004):

$$
\begin{aligned}
\theta & =1-f r_{\mathrm{m}}-f r_{\mathrm{u}}=\theta_{0} \cdot \frac{1+C_{\mathrm{m}}^{0} \cdot \frac{M_{\mathrm{m}}}{\rho_{\mathrm{m}}}}{1+C_{\mathrm{m}} \cdot \frac{M_{\mathrm{m}}}{\rho_{\mathrm{m}}}} \\
\frac{k}{k_{0}} & =\left(\frac{\theta}{\theta_{0}}\right)^{5.1},
\end{aligned}
$$

where $\theta$ is the porosity, $f r_{\mathrm{u}}$ is the volume fraction of unreactive media (sand), $f r_{\mathrm{m}}$ is the volume fraction of mineral (barite) in the medium, $\theta_{0}$ is the initial porosity, $C_{\mathrm{m}}^{0}$ is the initial molar concentration of the mineral ( $\mathrm{mol} /\left(\mathrm{L}\right.$ of fluid)), $C_{\mathrm{m}}$ is the current mineral concentration, $M_{\mathrm{m}}$ is the molecular weight of mineral $(\mathrm{g} / \mathrm{mol})$, and $\rho_{\mathrm{m}}$ is the density $\left(\mathrm{g} / \mathrm{cm}^{3}\right)$ of mineral.

Experimentally measured initial hydraulic conductivity and porosity values (shown in Table 1) were directly used in the numerical model as input, while dispersion coefficients were obtained by fitting the width of the mixing zone observed in the initial dye tracer tests. Strictly speaking, dispersion coefficient is a second-rank tensor. However, for estimation of dispersion coefficients, the only information available is the transverse width of the mixing zones observed in those dye tracer tests. In the simulations, it is critical to accurately replicate the transverse width of the mixing zone of dye tracers in order to reproduce the narrow precipitation bands observed in the experiments. The main transport mechanism within low permeability inclusions and along transverse direction perpendicular to flow is diffusion. Thus, in order to simplify the efforts of parameter estimation, we reduced the second-rank dispersion tensor to a single scalar dispersion coefficient in simulations. Apparent precipitation rate constants were fitted (values shown in Table 2) according to the spatial distribution of precipitates observed (recorded photographically) during the experiments. 
Table 1 Hydraulic conductivity and porosity values for Ottawa sands used in experiments

\begin{tabular}{llll}
\hline Mesh & Nominal grain size $(\mathrm{mm})$ & $K_{\mathrm{S}}(\mathrm{m} / \mathrm{s})$ & Porosity (vol/vol) \\
\hline $20^{*}$ & 0.850 & $2.42 \mathrm{E}-03$ & 0.36 \\
$20-30$ & $0.600-0.850$ & $1.13 \mathrm{E}-03$ & 0.36 \\
$50-70$ & $0.212-0.300$ & $1.38 \mathrm{E}-04$ & 0.38 \\
F110 & $\leq 0.150 \mathrm{~mm}$ & $4.63 \mathrm{E}-05$ & 0.40 \\
\hline
\end{tabular}

* 20- to 30-mesh sand that was sieved to $>25$ mesh but $<18$ mesh

Table 2 Dispersion coefficients and kinetic rate constants fitted for all cases

\begin{tabular}{|c|c|c|c|c|c|}
\hline & \multirow{2}{*}{$\begin{array}{l}\text { Homogeneous case } \\
\text { (20- to } 30 \text {-mesh sand) }\end{array}$} & \multicolumn{2}{|c|}{ Low permeability case } & \multicolumn{2}{|c|}{ High permeability case } \\
\hline & & $\begin{array}{l}\text { Inclusion F- } \\
110 \text { mesh sand }\end{array}$ & $\begin{array}{l}\text { Matrix 20- to } \\
\text { 30-mesh sand }\end{array}$ & $\begin{array}{l}\text { Inclusion 20- } \\
\text { mesh sand }\end{array}$ & $\begin{array}{l}\text { Matrix 50- to } \\
70 \text {-mesh sand }\end{array}$ \\
\hline $\begin{array}{l}\text { Dispersion } \\
\text { coefficient } \\
\left(\mathrm{m}^{2} / \mathrm{s}\right)\end{array}$ & $3.0 \mathrm{E}-7$ & $3.0 \mathrm{E}-08$ & $3.0 \mathrm{E}-07$ & $3.0 \mathrm{E}-07$ & $3.0 \mathrm{E}-08$ \\
\hline $\begin{array}{l}\text { Apparent rate } \\
\text { constant } R_{\text {ref }} \\
(\mathrm{mol} / \mathrm{L} / \mathrm{s})\end{array}$ & $1.08 \mathrm{E}-08$ & $1.0 \mathrm{E}-08$ & & $1.0 \mathrm{E}-09$ & \\
\hline
\end{tabular}

\section{Results and Discussion}

\subsection{Characterization of Porous Media}

Measured saturated hydraulic conductivity $\left(K_{\mathrm{S}}\right)$ and porosity values for the four different sand fractions used in the experiments are shown in Table 1.

The homogeneous flow cell was packed with 20- to 30-mesh sand. Hydraulic conductivity of the low permeability inclusion sand (F110 mesh) was $24 \times$ less than that of the matrix (surrounding) sand (20-30 mesh). Hydraulic conductivity of the high permeability inclusion sand (20 mesh) was $18 \times$ more than that of the matrix sand (50-70 mesh).

The fitted parameter values for dispersion coefficients and apparent precipitation rate constants used in the simulations are listed in Table 2. The contrasts between the dispersion coefficients for different materials used in the heterogeneous media experiments were due primarily to the hydraulic conductivity contrasts and to a lesser extent to the porosity contrasts between the coarse and the fine material used in the experiments. More detailed discussion of these relationships is provided by Xu and Eckstein (1997). The apparent rate constants $\left(R_{\text {ref }}\right.$ in Table 2) are lumped coefficients that reflect differences in the specific reactive surface area of the different sands used in the experiments.

\subsection{Precipitation Experiment: Homogeneous Case}

\subsubsection{Experimental Observations}

In the homogeneous sand pack experiment, a white precipitate was observed to form starting at the inlet end and then extending along the entire length of the flow cell within the first 3 pore volumes $\left(\sim 30 \mathrm{~min}\right.$ ) of $\mathrm{Ba}^{2+} \| \mathrm{SO}_{4}^{2-}$ injection (Fig. 4$)$. The mineral precipitation zone was relatively uniform in width $(<0.5 \mathrm{~mm})$ and symmetrically centered around the center of 


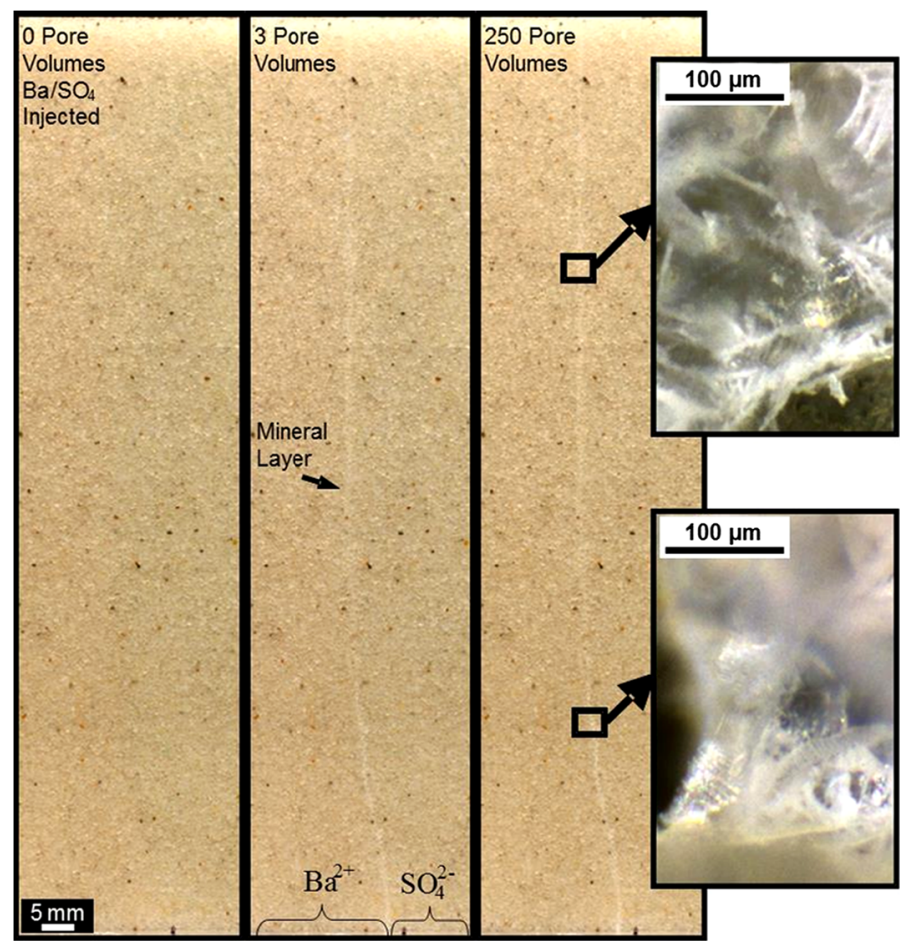

Fig. 4 Homogeneous flow cell. Insets are microscope images showing minerals formed during reactant injection $\left(\mathrm{Ba}^{2+}\right.$ on left and $\mathrm{SO}_{4}^{2-}$ on right $)$

the steady-state mixing interface (defined by the darkest color of mixed dyes—see "Before $\mathrm{Ba}^{2+} \| \mathrm{SO}_{4}^{2-}$ injection" in Fig. 5). No changes in the dimensions of the precipitation zone were observed between 3 pore volumes and the conclusion of the experiment ( 250 pore volumes; $\sim 48 \mathrm{~h}$ ), which suggests that either the precipitation zone had become impermeable and stable against dissolution, or the precipitate zone was at steady state where active precipitation/dissolution processes were limited to the narrow region where precipitate is visible. The parallel dye injection at the end of the experiment indicated that mixing across the mineral layer (transverse permeability) was diminished but was not completely eliminated (see panel "after 250 pore volumes of $\mathrm{Ba}^{2+} \| \mathrm{SO}_{4}^{2-}$ " in Fig. 5). With the exception of an initial segment immediately upstream from the injection boundary (in this case approximately the first two centimeters), the decrease in transverse permeability appeared to be relatively uniform along the length of the precipitation zone. That the precipitation zone retained a finite permeability is consistent with the discussion in Tartakovsky et al. (2008) concerning an "irreducible permeability" for parallel flow systems. In this system, each of the injected solutions is individually undersaturated with respect to the precipitated phase and would therefore be expected to dissolve both sides of the precipitation zone. Microscopic images taken at the end of the experiment showed what appeared to be a feathery or dendritic crystal phase within the sand along the length of the precipitation zone (Fig. 4, insets). A tendency toward dendritic morphology is consistent with diffusional control of precipitation kinetics (Dunn et al. 1999; Li et al. 2008). In reports for well-stirred systems (where surface-controlled, secondorder reaction kinetics are also observed), barite does not exhibit such dendritic structures 


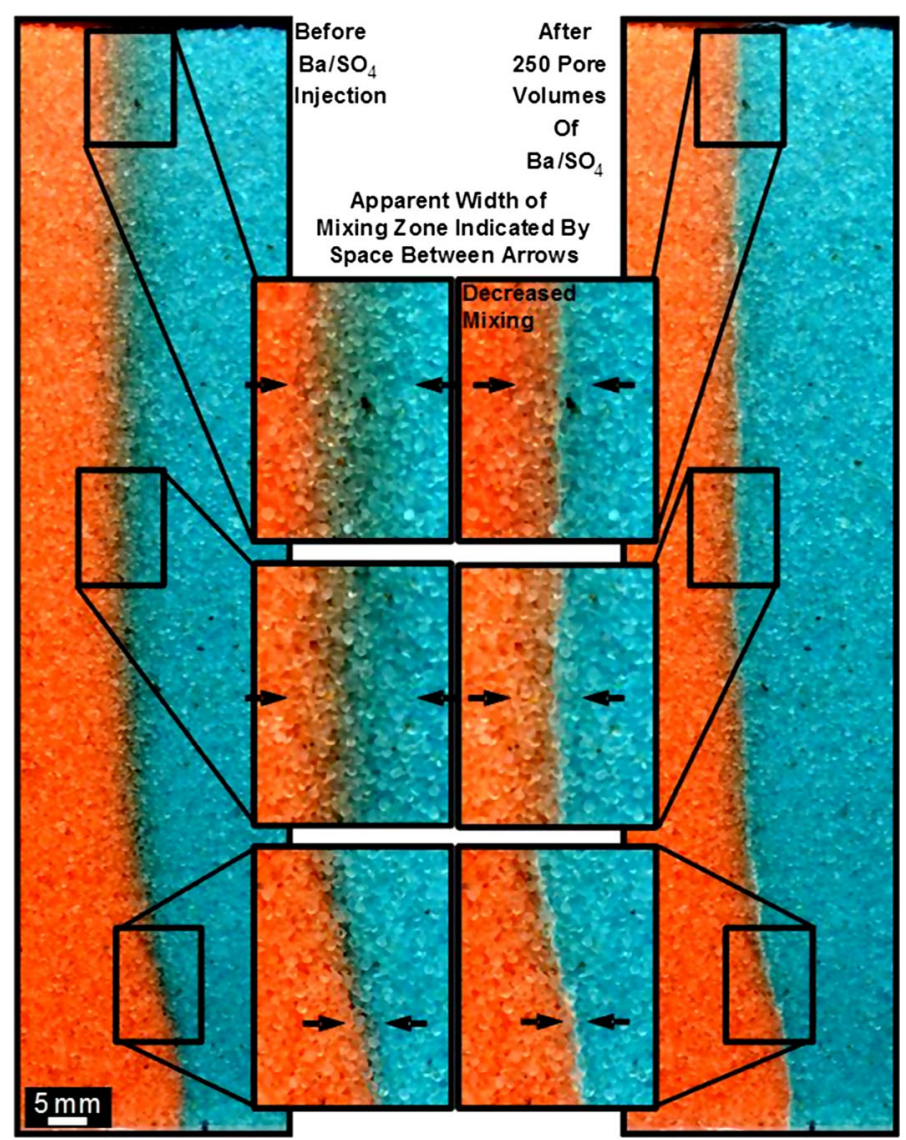

Fig. 5 Homogenous flow cell: transverse mixing at steady-state dye mixing (5 pore volumes)

(e.g., BinMerdhah et al. 2009; Dunn et al. 1999). However, Kowacz et al. (2007) demonstrated that dendritic growth can occur from solutions with high $\mathrm{Ba}^{2+} / \mathrm{SO}_{4}^{2-}$ ratios, and that the mechanisms of $\mathrm{BaSO}_{4}$ precipitation can be quite dependent on solution conditions.

\subsubsection{Numerical Simulations}

In simulations for the homogeneous medium, a uniform width of the precipitation zone was simulated with a corresponding decrease (but not elimination) of permeability where precipitation took place (Fig. 6a, b). The location and shape of the simulated precipitation zone (Fig. 6) are consistent with experimental observations shown in Fig. 5. Although not measured directly in the experiments, the simulation further reveals that the region with the highest concentration of precipitate $(16.35 \mathrm{~mol} / \mathrm{L})$ was located near the bottom of the domain where the solutions initially mixed, leading to a maximum reduction by $32 \%$ in porosity and $77 \%$ in permeability (Fig. 6b). The observed curvature in the precipitation zone is due to the higher injection rate of the $\mathrm{SO}_{4}^{2-}$ solution on the right compared to the injection rate of $\mathrm{Ba}^{2+}$ solution on the left as described in Sect. 2.3, and the resulting hydraulic pressure and velocity field are shown in Fig. 6c. 

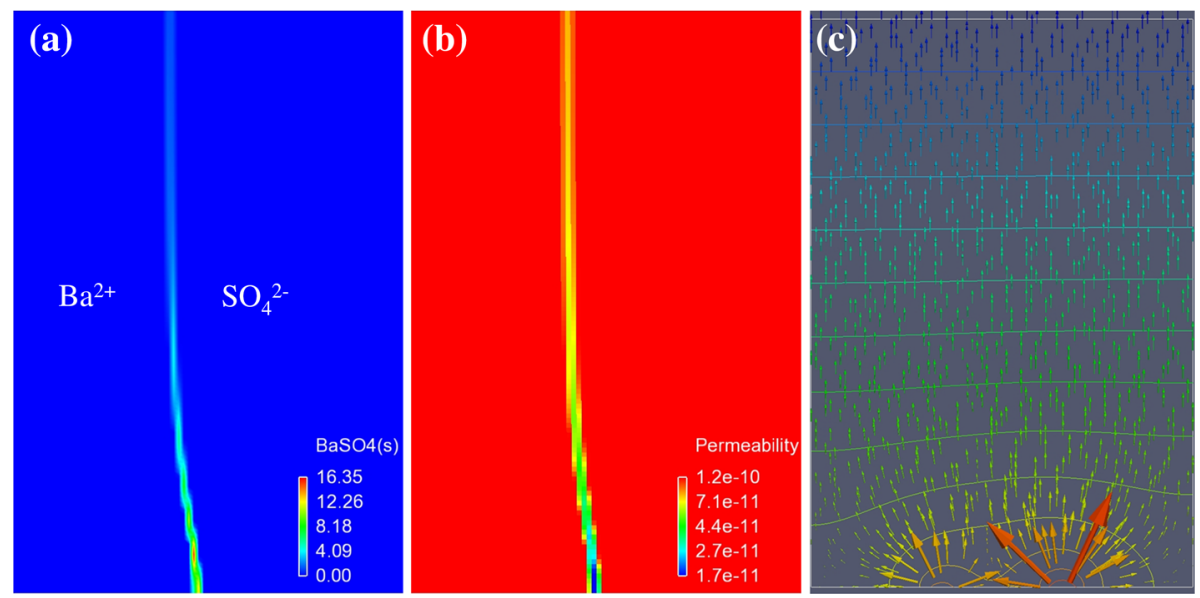

Fig. 6 Homogeneous flow cell simulations: (a) spatial distribution of barium sulfate precipitation (mol/L), (b) spatial distribution of permeability $\left(\mathrm{m}^{2}\right)$ and (c) hydraulic head contours and velocity field (where the relative size of arrows indicates magnitude of velocity and arrow orientation indicates local flow direction), at the end of the simulations (8 pore volumes)

\subsection{Low Permeability Inclusion Case}

\subsubsection{Experimental Observations}

For the flow cell containing a low permeability inclusion, a narrow $(<0.5 \mathrm{~mm})$ precipitate layer was visible up- and downstream of the inclusion within the first 3 pore volumes ( $\sim 30 \mathrm{~min}$ ) of $\mathrm{Ba}^{2+} \| \mathrm{SO}_{4}^{2-}$ injection (Fig. 7); because of the light color of the F-110 sand in the inclusion, it was difficult to discern whether the precipitate layer also transected the inclusion. As expected, the precipitate layer formed along the center of the steady-state mixing zone that had been defined using parallel dye injection before $\mathrm{Ba}^{2+} \| \mathrm{SO}_{4}^{2-}$ injection (indicated by white dashed lines in Fig. 8). No obvious changes in dimensions of the precipitation zone upstream of the inclusion were discernible in the photographic images after the first 3 pore volumes. However, between 3 and 5 pore volumes (20-min elapsed time) of injection, the formation of a mineral deposit outside of the inclusion on the $\mathrm{SO}_{4}^{2-}$ side (right side in the images) was observed and the precipitate deposition zone downstream of the inclusion broadened as visible mineral deposition progressed from left to right (Fig. 7). The broadening ceased within 8 pore volumes of injection, indicating establishment of a new "steady-state" mixing zone extending to the right of its initial location. No additional mineral deposition was observed between 8 and 250 pore volumes, nor was dissolution of $\mathrm{BaSO}_{4}$ solid apparent on the left side of the mixing zone downstream of the inclusion even though the $\mathrm{BaCl}_{2}$ solution on the left was undersaturated with respect to $\mathrm{BaSO}_{4}$ (s).

Comparison of dye mixing before and after $\mathrm{Ba}^{2+} \| \mathrm{SO}_{4}^{2-}$ injection shows that mixing occurred upstream of and within the inclusion prior to the precipitation experiment (indicated by red-blue mixed dye upstream of and within the inclusion in Fig. 8, left and middle panels). After 250 pore volumes of $\mathrm{Ba}^{2+} \| \mathrm{SO}_{4}^{2-}$ injection $(\sim 48 \mathrm{~h})$, upstream dye mixing appeared to be significantly decreased and essentially no mixing was observed across the precipitate layer within the inclusion (indicated by only red or blue dye in the inclusion, Fig. 8, inset a). The width of pre- and post-reaction mixing zones downstream of the inclusion are comparable although the post-reaction mixing zone is shifted right toward the $\mathrm{SO}_{4}^{2-}$ solution (as shown 


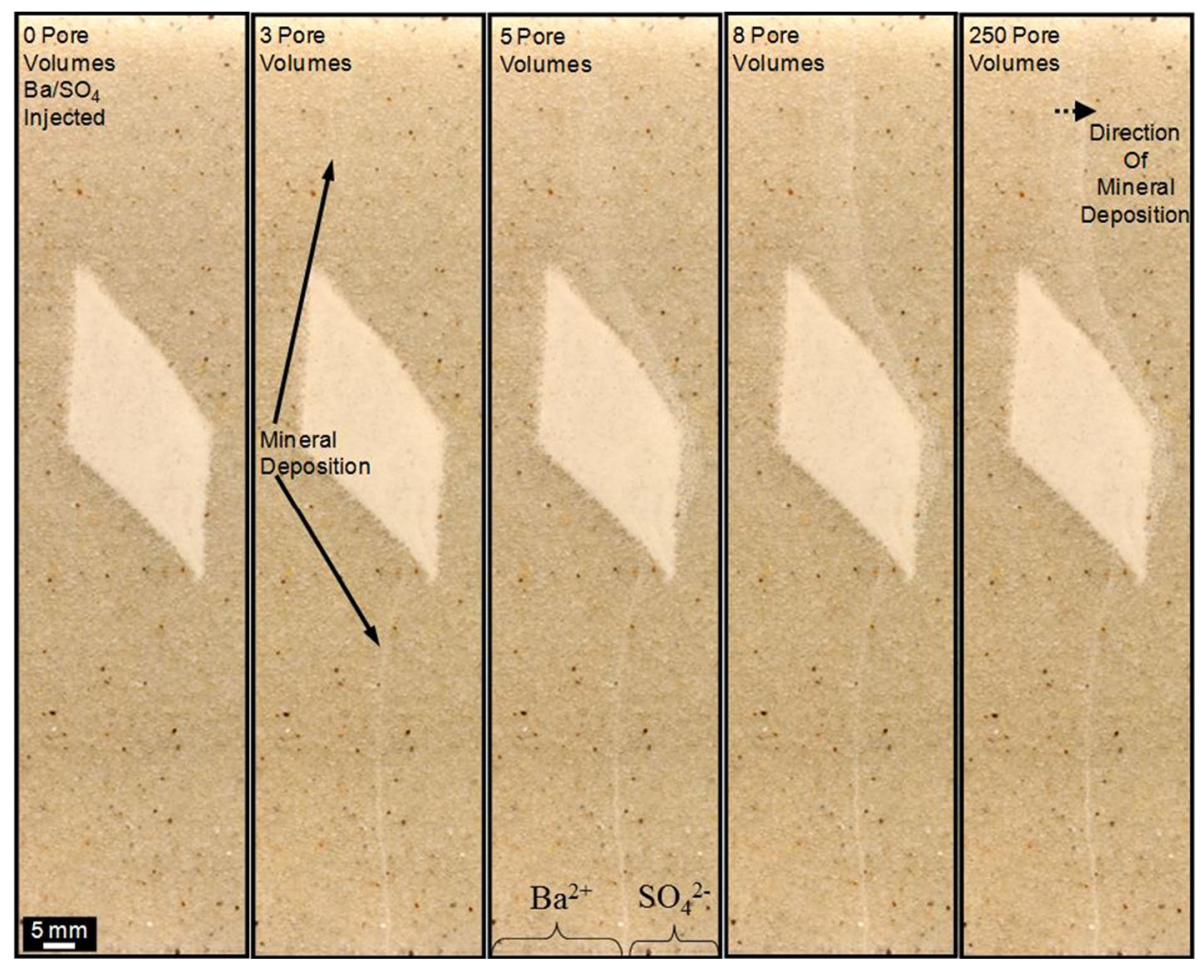

Fig. 7 Low permeability inclusion flow cell: cropped images showing mineral formation during reactant injection $\left(\mathrm{Ba}^{2+}\right.$ on left and $\mathrm{SO}_{4}^{-}$on right $)$

in the left- and right-most panels of Fig. 8). As in the homogenous case, the greatest decrease in transverse permeability appeared to be within the first $2 \mathrm{~cm}$ just downstream from the injection boundary (illustrated in Fig. 8, inset b). Overall, based on the dye injections, the precipitation zone appeared to be narrower and more sharply defined within the fine sand of the inclusion than within the coarser sand of the matrix (Fig. 8, inset a).

Post-experiment microscope images showed the narrow $(<0.5 \mathrm{~mm})$ mineral section upstream of the inclusion and regions downstream of the inclusion, where migration of the mixing zone initiated and terminated, appeared to be composed of relatively large $(\sim 100 \mu \mathrm{m})$ feathery dendritic crystals (Fig. 9), similar to those seen in the homogeneous experiment (Fig. 4). Inside the inclusion, we observed a narrower $(<50 \mu \mathrm{m})$ section of precipitates consisting of a finer crystal phase; however, image resolution was not sufficient to resolve the morphology of these precipitates (Fig. 10). The greater reduction in mixing within the inclusion as compared to the matrix (as illustrated in Fig. 8, inset a) suggested that the $\mathrm{BaSO}_{4}$ crystals precipitated within the inclusion were more effective at filling the local pore space, in a narrower band, than the crystals in the coarse grained matrix.

\subsubsection{Numerical Simulations}

Final-state simulation results, at the time after 8 pore volumes of injection, for mineral precipitate and media permeability distributions for the low permeability inclusion case are shown in Fig. 11a, b. We find 4 main features of the temporal and spatial distribution of 

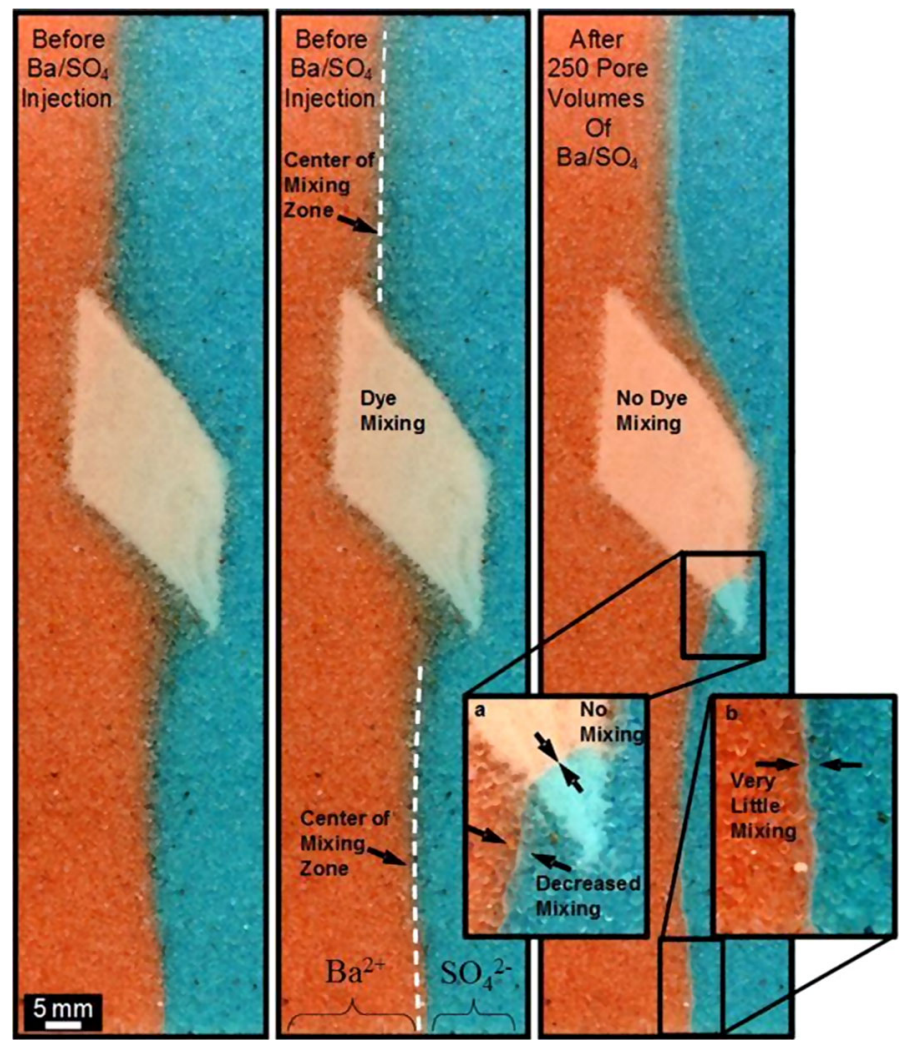

Fig. 8 Low permeability inclusion experiment: transverse mixing at 5 pore volumes of dye injection (inclusion is F110 mesh sand, and surrounding matrix is 20- to 30-mesh sand). Note: The middle panel is a copy of the left panel. White dashed lines were imposed on the copy to illustrate the location of the initial steady-state mixing zone's centerline

precipitation are captured in the low permeability inclusion simulations: (1) the curving of the mixing/precipitation zone upstream of the inclusion; (2) the precipitation deposit that forms along the inclusion's right (i.e., $\mathrm{SO}_{4}^{2-}$ ) edges; (3) the broadening of the precipitation zone downstream of the inclusion toward the $\mathrm{SO}_{4}^{2-}$ side (not shown in Fig. 11a as it shows only the final state); and (4) the significant reduction in permeability ( $\sim 2$ order of magnitude) due to mineral precipitation. These features captured by the simulations are in very good agreement with experimental observations.

The precipitation zone curves upstream of the inclusion due to the higher injection rate on the right side which pushes $\mathrm{SO}_{4}^{2-}$ solution toward the left $\left(\mathrm{Ba}^{2+}\right)$ side; this is the same as seen in the homogeneous case. Further downstream, immediately upstream of the inclusion, flow diverges to the right due to the low permeability media in the inclusion; Fig. 11c shows the steady-state velocity field. The $\mathrm{Ba}^{2+}$ solution is transported by both advection and dispersion around and through the inclusion, while $\mathrm{SO}_{4}^{2-}$ solution flows mostly around the right edge. Very limited $\mathrm{SO}_{4}^{2-}$ transport into the inclusion by dispersion takes place, resulting in a bias of the mixing zone position and subsequent precipitate formation toward the $\mathrm{SO}_{4}^{2-}$ side of the inclusion. Downstream of the inclusion, we find the initial location of the mixing/precipitation zone is determined by the faster (compared to $\mathrm{Ba}^{2+}$ ) $\mathrm{SO}_{4}^{2-}$ advective transport that causes a 


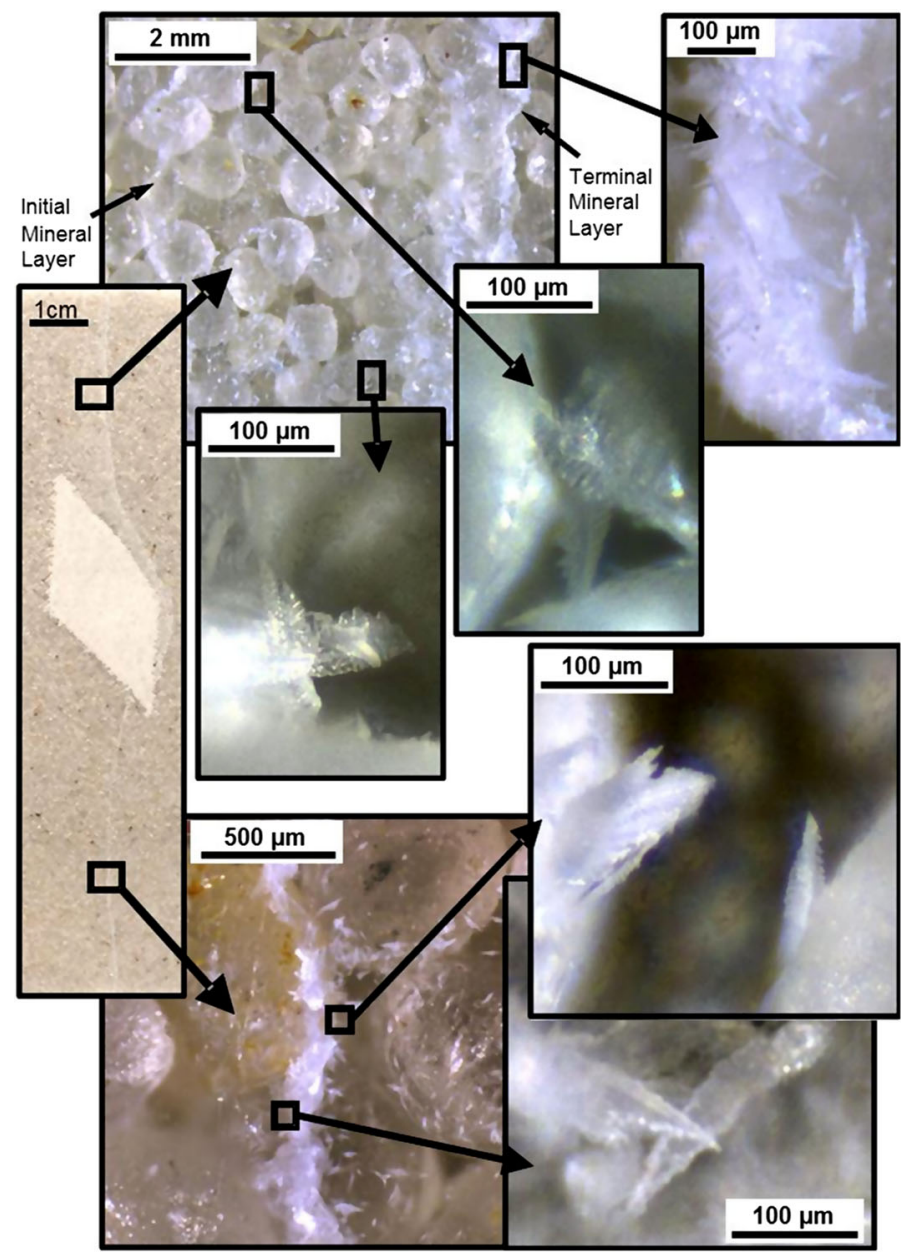

Fig. 9 Low permeability inclusion flow cell: optical microscope images of precipitated minerals upstream and downstream of inclusion after 250 pore volumes of reactant injection

left trending $\mathrm{SO}_{4}^{2-}$ solution flow that merges with the $\mathrm{Ba}^{2+}$ solution (the left trending $\mathrm{SO}_{4}^{2-}$ flow is indicated by the velocity field shown in Fig. 11c). The downstream broadening of the mixing/precipitation zone toward the $\mathrm{SO}_{4}^{2-}$ side occurs as the dispersive transport of $\mathrm{Ba}^{2+}$ solution through the inclusion slowly takes place. We investigated the downstream precipitation zone evolution by recording the peak precipitate concentration over time along the horizontal, dashed white-line segment shown in Fig. 11a that intersects the precipitation zone downstream of the inclusion. The line segment is located at y-coordinate $0.11 \mathrm{~m}$ and $x$-coordinates $0.025-0.045 \mathrm{~m}$ of the experimental cell and modeling domain. Figure 12 shows the change in the location of peak precipitate concentration downstream of the low permeability inclusion; the peak precipitate position (normalized by the width of flow cell) moves toward the right side of the flow cell rapidly at first and slows down over time (in equivalent pore volume) and eventually becomes stable after $2760 \mathrm{~s}$. This time is equivalent to $\sim 4$ pore volumes of injection and is consistent with when visible broadening of the downstream precipitation zone started to be observed, as shown in Fig. 7. The overall maximum relative 


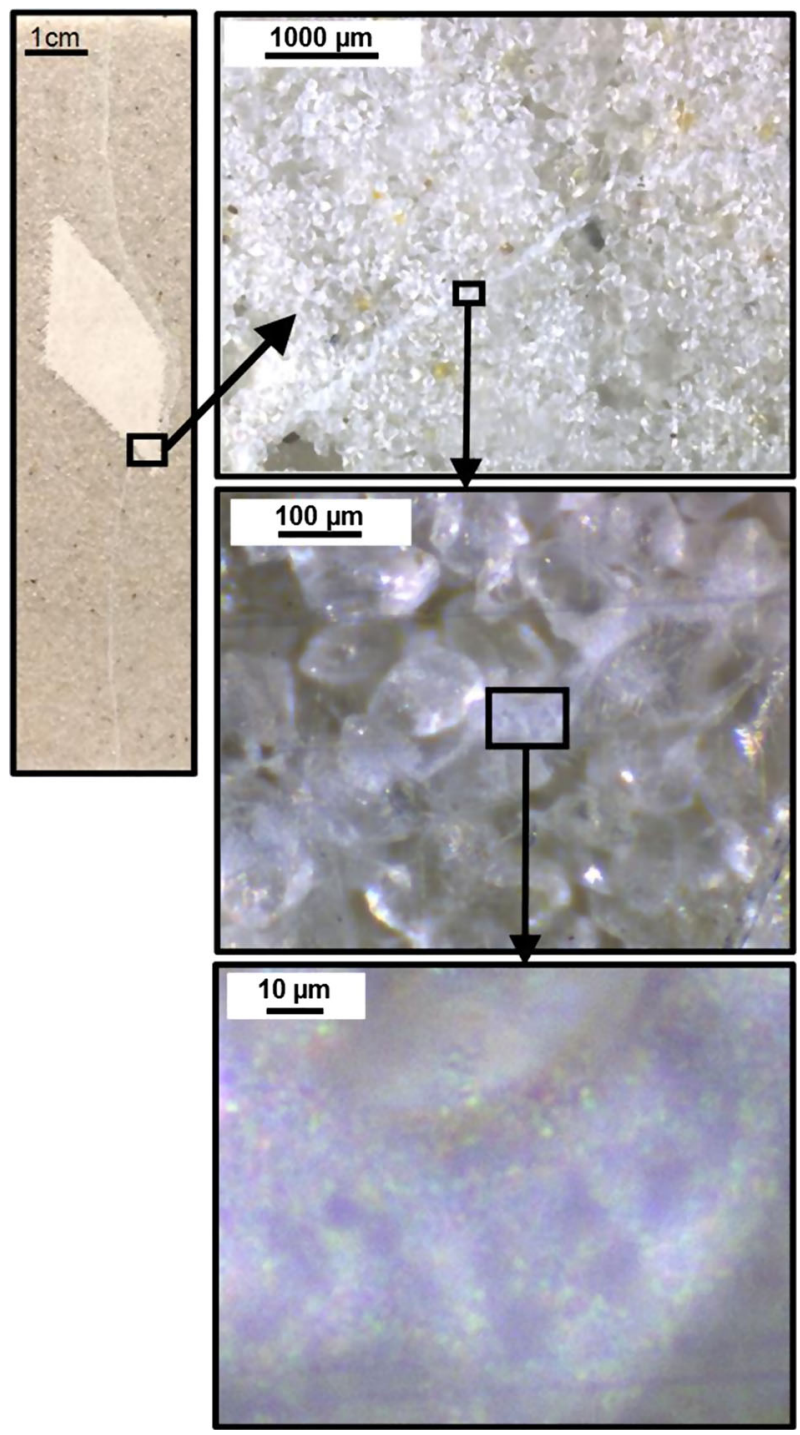

Fig. 10 Low permeability inclusion flow cell: optical microscope images of precipitated minerals in inclusion after 250 pore volumes of reactant injection

reduction in porosity (by $50 \%$ ) and permeability (by $95.2 \%$ ) occurs upstream of the inclusion near the injection boundary (Fig. 11b), whereas in the homogeneous case, the reactants were at their highest concentration and had the longest time to mix and form precipitates.

\subsection{High Permeability Inclusion Case}

\subsubsection{Experimental Observations}

For the flow cell with a high permeability inclusion, a precipitate deposition zone was visible along the entire length of the sand pack within the first 3 pore volumes $(\sim 30 \mathrm{~min})$ of 

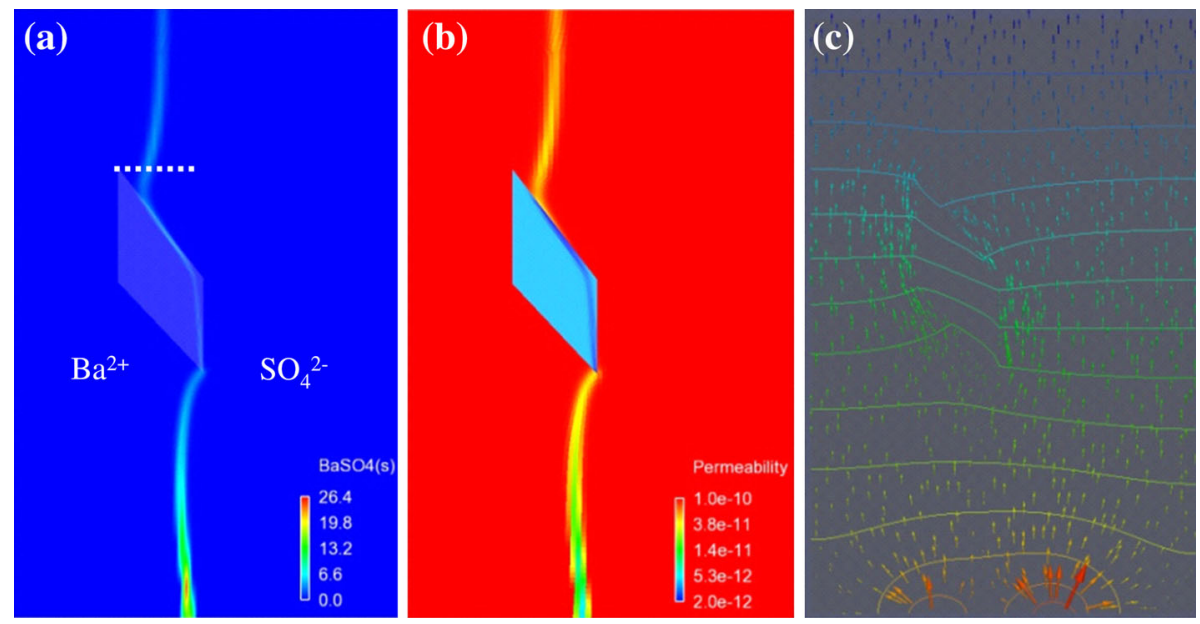

Fig. 11 Low permeability inclusion flow cell simulations: (a) spatial distribution of barium sulfate precipitation (mol/L), (b) spatial distribution of permeability $\left(\mathrm{m}^{2}\right)$ and (c) hydraulic head contours and velocity field (where the relative size of arrows indicates magnitude of velocity and arrow orientation indicates local flow direction), at the end of the simulations (8 pore volumes). The horizontal dashed white line in (a) indicates the line segment along which the precipitation profile was sampled and investigated for temporal variations (shown in Fig. 12)

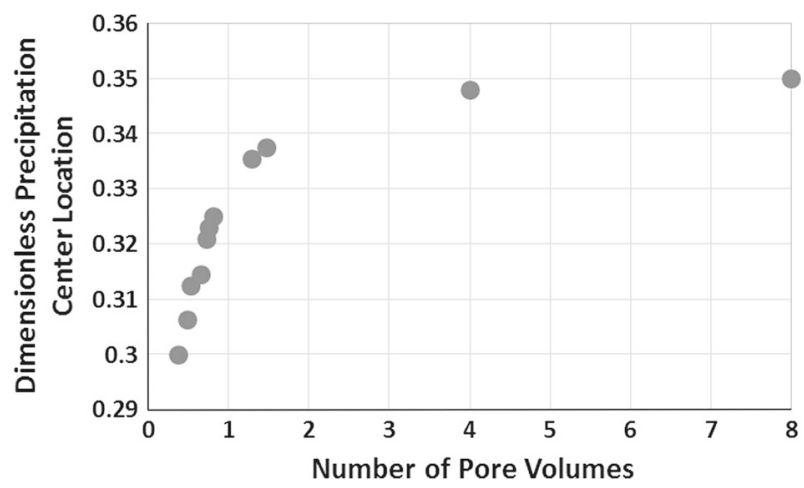

Fig. 12 Changes of maximum precipitation location with time along the line segment shown as a white dotted line in Fig. 11a

$\mathrm{Ba}^{2+} \| \mathrm{SO}_{4}^{2-}$ injection (Fig. 13). No lateral migration of the mixing/precipitation zone, and very little additional precipitation, was observed during the period between 3 pore volumes and the conclusion of the experiment ( 250 pore volumes, $\sim 48 \mathrm{~h}$ ). As expected, the precipitate deposited along the center of the steady-state mixing zone as defined by the pre-experiment parallel dye injection (see "before $\mathrm{Ba}^{2+} \| \mathrm{SO}_{4}^{2-}$ injection" in Fig. 14). Similar to the low permeability inclusion case, the width of precipitate deposition zone varied with grain size. The precipitation zone appeared uniform in width $(<0.5 \mathrm{~mm})$ upstream and downstream of the inclusion but was wider $(\sim 1.0 \mathrm{~mm})$ within the inclusion. Within the inclusion, the width of the precipitate deposition zone (Fig. 14, right inset) was less than the width of the mixing zone that had been observed during the initial dye injection (Fig. 14, left inset). Greater initial 


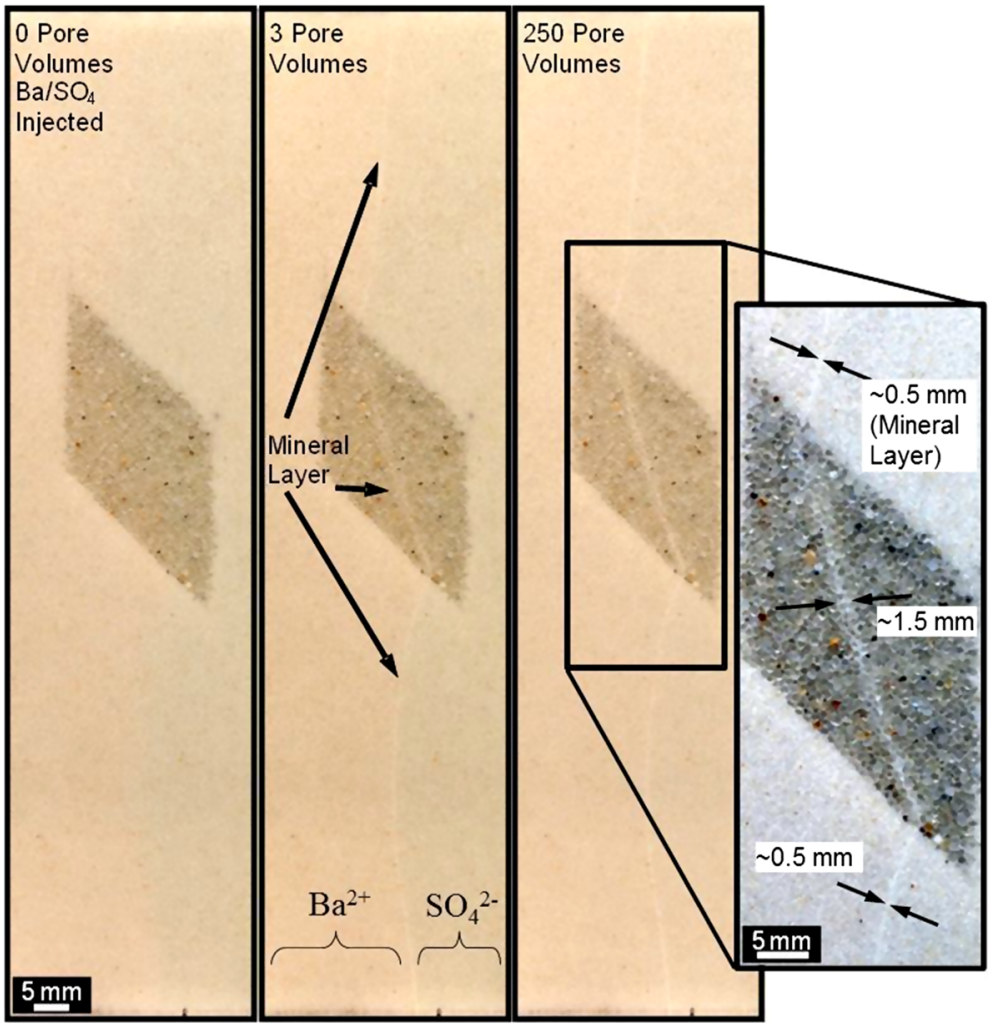

Fig. 13 High permeability inclusion flow cell: cropped images showing mineral formation during reactant injection $\left(\mathrm{Ba}^{2+}\right.$ on left and $\mathrm{SO}_{4}^{2-}$ on right). The contrast in the image shown in the inset was enhanced to better show the mineral layer within and on both sides of the inclusion

dispersion within and downstream of the high permeability inclusion is consistent with the dependence of dispersion on velocity (which is higher in and downstream of the inclusion) observed by Rolle et al. (2009) and with the dependence on grain size recorded by Xu and Eckstein 1997. After precipitation in the high permeability inclusion experiment, transverse mixing appeared to be uniform along the length of the interface, even in the inclusion (Fig. 14, right inset). This uniformity suggests that the inclusion's relatively wide precipitation zone (Fig. 13, inset) influenced transverse mixing in the larger grained inclusion to a similar extent as the narrow precipitation zone within the smaller grained matrix. This contrasts with the observations in the low permeability inclusion experiment, where transverse mixing was decreased to a greater extent in the finer grained material (Fig. 8, inset a) and resulted in the non-uniform width of the mixing zone along the length of the interface.

\subsubsection{Numerical Simulations}

Final-state simulation results of mineral precipitate and media permeability distributions at the time of 8 pore volumes of injection for the high permeability inclusion case are shown in Fig. 15a, b. Again, features captured by the simulations are in agreement with visual experimental observations. Main features for this case are the following: (1) the curvature of the 


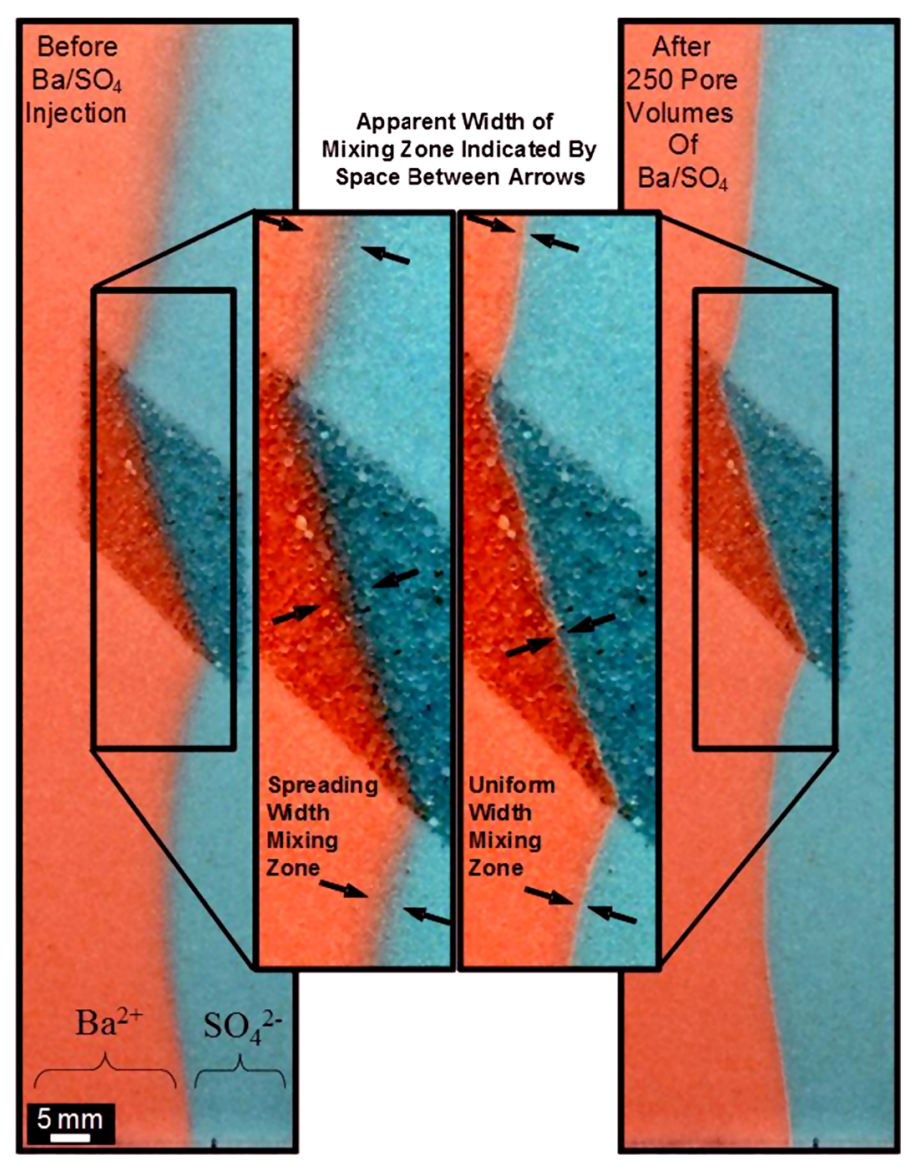

Fig. 14 High permeability inclusion flow cell: transverse mixing at 5 pore volumes of dye injection

precipitation zone upstream of the inclusion, (2) the wider precipitation layer inside the inclusion, (3) the reduction in permeability due to mineral precipitation and (4) hydraulic refraction of the mixing/precipitation zone as it transects boundaries of contrasting permeability.

Formation of a wider precipitate layer in the inclusion compared to the matrix is due to the higher dispersion coefficient associated with the inclusion's higher permeability media (inclusion permeability $18 \times$ higher than the matrix). Other authors (Werth et al. 2006; Willingham et al. 2008) have also reported mixing enhancement through streamline focusing in porous media systems with high permeability heterogeneities. The location of maximum relative porosity and permeability reductions (by 41.2 and $87.9 \%$, respectively) is in the inclusion, due to streamline focusing and the subsequent relatively wide zone of precipitation compared to the matrix. This is in contrast to the homogeneous and low permeability inclusion cases where the location of maximum relative permeability reduction (77 and $95.2 \%$, respectively) is at the bottom of the cell, due to the longer time of mixing near the injection boundary.

The mixing zone's "left leaning" orientation inside the inclusion that is observed in the experiment (Fig. 13) is due to hydraulic refraction of streamlines across the matrix-inclusion interface (Fig. 15c). For the same reason, when the two solutions are transported out of the inclusion through the downstream interface, streamline refraction causes a "right leaning" 

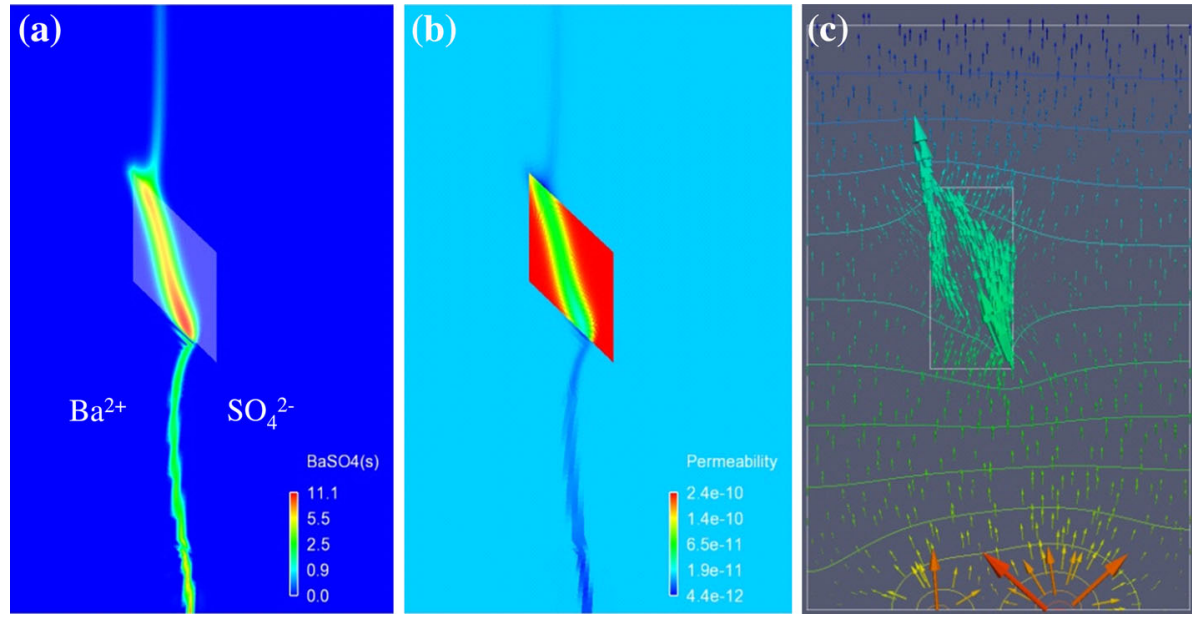

Fig. 15 High permeability inclusion flow cell simulations: (a) spatial distribution of barium sulfate precipitation ( $\mathrm{mol} / \mathrm{L})$, (b) spatial distribution of permeability $\left(\mathrm{m}^{2}\right)$ and $(\mathbf{c})$ hydraulic head contours and velocity field (where the relative size of arrows indicates magnitude of velocity and arrow orientation indicates local flow direction), at the end of the simulations ( 8 pore volumes)

orientation of the mixing zone. The simulation results are in satisfactory agreement with visual experimental observations.

\section{Conclusions}

Laboratory experiments were performed to investigate mixing and barite mineral precipitation under the conditions of parallel flowing reactive solutions (barium chloride and sodium sulfate) in 2-dimensional flow cells containing quartz sand with and without physical heterogeneities. The main objective was to study the impact of physical heterogeneity on reactant mixing and geochemical processes.

We observed that pore-space filling by $\mathrm{BaSO}_{4}$ could be dependent on the sand grain size since precipitate morphology is influenced by the rate of diffusive reactant transport. In the 20-mesh $(0.850 \mathrm{~mm})$ and 20 - to $30(0.850-0.600 \mathrm{~mm})$-mesh sands, dendritic crystals were observed that were on the order of $100 \mu \mathrm{m}$ in size. This dimension is similar to the size of the F110 sand grains used in the inclusion for the low permeability inclusion experiment $(\leq 0.150 \mathrm{~mm})$. Precipitation in that medium appeared to result in a low permeability barrier to transverse mixing. Similarly, precipitation in 50- to 70-mesh sand $(0.300-0.212 \mathrm{~mm})$ used as the matrix in the high permeability inclusion experiment resulted in significantly reduced transverse mixing, though to a lesser extent than in the F110 sand. In the larger grained media (i.e., 20-30 mesh), with larger pore spaces, pore-space filling or perhaps grain cementation by the precipitates was not as significant although transverse mixing was still reduced.

Both experimental and modeling results clearly indicate that physical heterogeneity has a profound impact on the shape, width and dynamics of the mixing zone between precipitateforming reactants. Our results illustrate: (1) the phenomenon of precipitate zone widening as parallel flowing reactant solutions converge in a relatively high permeability inclusion, due to enhanced dispersive mixing from streamline focusing; and (2) the migration, transverse to flow, of precipitate deposits downstream of a relatively low permeability heterogeneity, 
due to alterations in local permeability and subsequent spatial changes in reactant solution flow upstream of the heterogeneity. The close agreement between experimental observations and model simulations provides confidence that the coupling between the important physical and chemical processes for a parallel flow regime with a simple chemical system is well understood, and provides a robust foundation on which to investigate systems with similar physical geometry but more complex chemistry.

Acknowledgments This research was conducted under DOE Idaho Operations Office Contract DEAC07-05ID14517 with funding provided by the US Department of Energy, Office of Science, Subsurface Biogeochemical Research Program. G.R. and Y.F. would also like to express their deep gratitude to the NanoGeoScience program at Copenhagen University for facilitating their contributions to the preparation of this manuscript, and especially to the National Bank of Denmark for helping to make their residence with Copenhagen University possible.

Open Access This article is distributed under the terms of the Creative Commons Attribution 4.0 International License (http://creativecommons.org/licenses/by/4.0/), which permits unrestricted use, distribution, and reproduction in any medium, provided you give appropriate credit to the original author(s) and the source, provide a link to the Creative Commons license, and indicate if changes were made.

\section{References}

Auset, M., Keller, A.A.: Pore-scale processes that control dispersion of colloids in saturated porous media. Water Resour. Res. 40(3) (2004). doi:10.1029/2003WR002800

BinMerdhah, A.B., Yassin, A.A.M., Muherei, M.A.: Laboratory and prediction of barium sulfate scaling at high-barium formation water. J. Petrol. Sci. Eng. 70(1-2), 74-83 (2009)

Blount, C.W.: Barite solubilities and thermodynamic quantities up to 300-degrees-C and 1400-bars. Am. Mineral. 62(9-10), 942-957 (1977)

Bozau, E., Häubler, S., van Berk, W.: Hydrogeochemical modelling of corrosion effects and barite scaling in deep geothermal wells of the North German Basin using PHREEQC and PHAST. Geothermics 53, 540-547 (2015)

Brecevic, L., Kralj, D.: On calcium carbonates: from fundamental research to application. Croat. Chem. Acta 80(3-4), 467-484 (2007)

Christy, A.G., Putnis, A.: The kinetics of barite dissolution and precipitation in water and sodium-chloride brines at 44-85- ${ }^{\circ} \mathrm{C}$. Geochim. Cosmochim. Acta 57(10), 2161-2168 (1993)

Curti, E., Fujiwara, K., Iijima, K., Tits, J., Cuesta, C., Kitamura, A., Glaus, M.A., Muller, W.: Radium uptake during barite recrystallization at $23+/-2{ }^{\circ} \mathrm{C}$ as a function of solution composition: An experimental Ba-133 and Ra-226 tracer study. Geochim. Cosmoch. Acta 74(12), 3553-3570 (2010)

De Muynck, W., De Belie, N., Verstraete, W.: Microbial carbonate precipitation in construction materials: a review. Ecol. Eng. 36(2), 118-136 (2010)

DeJong, J.T., Fritzges, M.B., Nusslein, K.: Microbially induced cementation to control sand response to undrained shear. J. Geotech. Geoenviron. Eng. 132(11), 1381-1392 (2006)

Dunn, K., Daniel, E., Shuler, P.J., Chen, H.J., Tang, Y., Yen, T.F.: Mechanisms of surface precipitation and dissolution of barite: a morphology approach. J. Colloid Interface Sci. 214(2), 427-437 (1999)

Fernandez-Gonzalez, A., Carneiro, J., Katsikopoulos, D., Prieto, M.: Thermodynamic properties of the (Ba, $\mathrm{Pb}) \mathrm{SO}_{4}$ solid solution under ambient conditions: implications for the behavior of $\mathrm{Pb}$ and $\mathrm{Ra}$ in the environment. Geochim. Cosmochim. Acta 105, 31-43 (2013)

Ferris, F.G., Stehmeier, L.G., Kantzas, A., Mourits, F.M.: Bacteriogenic mineral plugging. J. Can. Pet. Technol. 35(8), 56-61 (1996)

Fujita, Y., Taylor, J.L., Gresham, T.L.T., Delwiche, M.E., Colwell, F.S., McLing, T.L., Petzke, L.M., Smith, R.W.: Stimulation of microbial urea hydrolysis in groundwater to enhance calcite precipitation. Environ. Sci. Technol. 42(8), 3025-3032 (2008)

Gaston, D., Guo, L., Hansen, G., Huang, H., Johnson, R., Knoll, D., Newman, C., Park, H.K., Podgorney, R., Tonks, M., Williamson, R.: Parallel algorithms and software for nuclear, energy, and environmental applications. Part I: multiphysics algorithms. Commun. Comput. Phys. 12(3), 807-833 (2012a)

Gaston, D., Guo, L., Hansen, G., Huang, H., Johnson, R., Knoll, D., Newman, C., Park, H.K., Podgorney, R., Tonks, M., Williamson, R.: Parallel algorithms and software for nuclear, energy, and environmental applications. Part II: multiphysics software. Commun. Comput. Phys. 12(3), 834-865 (2012b) 
Guo, L., Huang, H., Gaston, D., Permann, C., Andrs, D., Redden, G., Lu, C., Fox, D., Fujita, Y.: A parallel, fully coupled, fully implicit solution to reactive transport in porous media using the preconditioned Jacobian-Free Newton-Krylov method. Adv. Water Resour. 53, 101-108 (2013)

Katz, G.E., Berkowitz, B., Guadagnini, A., Saaltink, M.W.: Experimental and modeling investigation of multicomponent reactive transport in porous media. J. Contam. Hydrol. 120-21, 27-44 (2011)

Kowacz, A., Putnis, C., Putnis, A.: The effect of cation:anion ratio in solution on the mechanism of barite growth at constant supersaturation: role of the desolvation process on the growth kinetics. Geochim. Cosmochim. Acta 71(21), 5168-5179 (2007)

Leung, W.H., Nancollas, G.H.: Kinetic study of seeded growth of barium-sulfate in presence of additives. J. Inorg. Nucl. Chem. 40(11), 1871-1875 (1978)

Li, X., Huang, H., Meakin, P.: Level set simulation of coupled advection-diffusion and pore structure evolution due to mineral precipitation in porous media. Water Resour. Res. 44(12) (2008). doi:10.1029/ 2007WR006742

Moore, R.C., Szecsody, J.E., Truex, M.J., Helean, K.B., Bontchev, R., Ainsworth, C.C.: Formation of nanosize apatite crystals in sediment for containment and stabilization of contaminants, environmental applications of nanomaterials. In: Fryxell, G.E., Cao, G. (eds.) Environmental Applications of Nanomaterials, pp. 89110. Imperial College Press, London (2007)

Rolle, M., Eberhardt, C., Chiogna, G., Cirpka, O.A., Grathwohl, P.: Enhancement of dilution and transverse reactive mixing in porous media: experiments and model-based interpretation. J. Contam. Hydrol. 110(34), 130-142 (2009)

Szecsody, J.E., Truex M.J., Zhong L., Johnson T.C., Qafoku N.P., Williams M.D., Greenwood W.J., Wallin E.L., Bargar J.D., Faurie D.K.: Geochemical and geophysical changes during ammonia gas treatment of vadose zone sediments for uranium remediation. Vadose Zone J. 11(4) (2012). doi:10.2136/vzj2011. 0158

Taron, J., Elsworth, D.: Thermal-hydrologic-mechanical-chemical processes in the evolution of engineered geothermal reservoirs. Int. J. Rock Mech. Min. Sci. 46(5), 855-864 (2009)

Tartakovsky, A.M., Redden, G., Lichtner, P.C., Scheibe, T.D., Meakin, P.: Mixing-induced precipitation: Experimental study and multiscale numerical analysis. Water Resour. Res. 44(6) (2008). doi:10.1029/ 2006WR005725

Warren, L.A., Maurice, P.A., Parmar, N., Ferris, F.G.: Microbially mediated calcium carbonate precipitation: implications for interpreting calcite precipitation and for solid-phase capture of inorganic contaminants. Geomicrobiol. J. 18(1), 93-115 (2001)

Werth, C.J., Cirpka, O.A., Grathwohl, P.: Enhanced mixing and reaction through flow focusing in heterogeneous porous media. Water Resour. Res. 42(12) (2006). doi:10.1029/2005WR004511

Willingham, T.W., Werth, C.J., Valocchi, A.J.: Evaluation of the effects of porous media structure on mixingcontrolled reactions using pore-scale modeling and micromodel experiments. Environ. Sci. Technol. 42(9), 3185-3193 (2008)

$\mathrm{Xu}$, M., Eckstein, Y.: Statistical analysis of the relationships between dispersivity and other physical properties of porous media. Hydrol. J. 5(4), 4-20 (1997)

Yeh, G.T., Tripathi, V.S.: A critical-evaluation of recent developments in hydrogeochemical transport models of reactive multichemical components. Water Resour. Res. 25(1), 93-108 (1989)

Zhang, T., Gregory, K., Hammack, R.W., Vidic, R.D.: Co-precipitation of radium with barium and strontium sulfate and its impact on the fate of radium during treatment of produced water from unconventional gas extraction. Environ. Sci. Technol. 48(8), 4596-4603 (2014) 